\title{
Use Of Invasive Blood Pressure Monitoring In Asymptomatic Mildly Hypotensive Cardiac Patients
}

Bharat Rawat, Prof D. B. Karki, Abhinav Vaidhya, Jessen Gurung. Ajay Shah, Subhash Acharya, Harminder Singh Sodhi, Minalma Pandey, Rajib Pande

\section{Background}

Beta-blockers and Angiotensin Converting Enzme Inhibitor (ACE-I) are still underused drugs by CAD or CHF patients. ' Patients with mild hypotension (noninvasive Systolic Blood Pressure (SBP): $80-90 \mathrm{~mm} \mathrm{Hg}$ ) are often not prescribed these medications.

\section{Methods}

Seventy-two patients of Myocardial Infarction or Congestive Heart Failure with asymptomatic mild hypotension who were not on betablockers or ACE-I were subjected to intra-arterial pressure monitoring system using SIEMENS 6002 monitors, Beta-blockers. (Metoprolol. Carvedilol) and/or ACE-II (Captopril, or Enalapril) were started and gradually stepped up over a period of 48 to 96 hours.

\section{Results}

There was a significant difference of Systolic Blood Pressure (average of $22.4 \mathrm{~mm} \mathrm{Hg}$ higher with invasive monitoring, with a range of 6 to $34 \mathrm{~mm} \mathrm{Hg}$ ). Diastolic Blood Pressure was not very different $(-4 \mathrm{~mm}$ to $+10 \mathrm{~mm} \mathrm{Hg}$ ). After a mean period of 3.2 (2 to 5 days) monitoring and careful titration. $16(22.2 \%)$ patients successfully tolerated beta-blockers (metoprolol, mean daily dose: $62.5 \mathrm{mg}$. orcarvedilol, mean daily dose: $9.3 \mathrm{mg}$ ), 12 (16.6\%) patients tolerated ACE: I (captopril, mean daily dose: $37.5 \mathrm{mg}$ ) and 32 (44.4\%) patients could tolerated both. Thus, 60 out of $72(83.3 \%)$ patients could be offered betablockers, ACE-I or both. 
- NEPALESE HEART JOURNAL

\section{Conclusions}

Patients of Myocardial Infarction or Congestive Heart Failure may have lower non-invasively Measured Systolic Blood Pressure. Many of the asymptomatic mildly hypotensive patients may be offered the benefit of ACE-I and/or Beta- blockers by careful short-term invasive Blood Pressure Monitoring.

Norvics Escorts international Hospital, Kathmandu; Nepal. 